\title{
Spontaneous Early Resolution of an latrogenic Type A Aortic Dissection Following Coronary Angiography
}

\author{
Yavuzer Koza, MD ${ }^{1}$ Uğur Kaya, MD ${ }^{2}$ Hakan Taş, MD ${ }^{1}$ Enise Armagan Koza, MD \\ ${ }^{1}$ Department of Cardiology, Ataturk University Faculty of Medicine, \\ Erzurum, Turkey \\ ${ }^{2}$ Department of Cardiovascular Surgery, Ataturk University Faculty of \\ Medicine, Erzurum, Turkey \\ ${ }^{3}$ Department of Anesthesiology, Erzurum Regional Training and \\ Research Hospital, Erzurum, Turkey \\ Address for correspondence Yavuzer Koza, MD, Department of \\ Cardiology, Ataturk University Faculty of Medicine, Yakutiye, Erzurum \\ 25100, Turkey (e-mail: yavuzerkoza@hotmail.com). \\ AORTA 2018;6:142-144.
}
Abstract
Keywords
- iatrogenic aortic dissection
- coronary angiography
- aorta
- medical therapy

A 74-year-old man was admitted with the diagnosis of non-ST-elevation myocardial infarction. During right coronary angiography, a coronary artery dissection extending into the proximal ascending aorta was noticed without hemodynamic compromise. Immediate computed tomography angiography showed no evidence of dissection in the ascending aorta. The patient remained hemodynamically stable with medical therapy alone. This case report highlights the importance of medical therapy in patients with uncomplicated iatrogenic aortic dissection.

\section{Introduction}

Aortocoronary dissections occur most commonly during retrograde percutaneous coronary intervention of chronic total occlusions (CTOs) due to more aggressive and extensive osteal atherosclerosis. Indeed, the most common cause of iatrogenic aortic dissections (IADs) is guiding catheter tip trauma. ${ }^{1}$ Iatrogenic dissections of the coronary artery and ascending aorta are very rare complications of diagnostic coronary angiography with an incidence of $0.02 \%{ }^{2}$ Here, we report the uneventful clinical outcome with conservative management of a patient with catheter-induced acute aortic dissection originating from the right coronary artery (RCA).

\section{Case Presentation}

A 74-year-old man was hospitalized with the diagnosis of non-ST-elevation myocardial infarction. Diagnostic coronary angiography showed $100 \%$ stenosis of left anterior descending (LAD) artery with retrograde flow to the RCA and $80 \%$ stenosis in obtuse marginal branch of the left circumflex artery. During the right coronary angiogram in right anterior oblique position, to confirm RCA occlusion, a coronary artery dissection extending into the proximal ascending aorta was noticed without hemodynamic compromise. (-Fig. 1A, B). Transthoracic echocardiography demonstrated no pericardial effusion. Immediate computed tomographic angiography showed no evidence of dissection in the ascending aorta (-Fig. 2A-D). The initial and subsequent echocardiogram examinations showed no pericardial effusion or dissection flap. Because the patient was stable with an intact aortic valve and aorta, we decided to pursue a conservative management strategy. Coronary artery bypass surgery was planned for his coronary lesions. A saphenous vein graft to the obtuse marginal branch of the circumflex artery and a left internal thoracic artery to the LAD coronary artery were performed. There was no evidence of the dissection in the aorta (-Fig. 3). The patient tolerated the surgery well and was discharged 10 days later.

\section{Discussion}

Clinical manifestations of IADs may vary from an asymptomatic angiographic finding to a complete hemodynamic collapse owing to the closure of the coronary ostium. ${ }^{2,3}$ Occurrence of IAD can be prevented by avoiding aggressive received

September 20, 2017 accepted after revision November 9, 2018
DOI https://doi.org/

10.1055/s-0039-1683956. ISSN 2325-4637.
Copyright $\odot 2018$ by Thieme Medical

Publishers, Inc., 333 Seventh Avenue, New York, NY 10001, USA. Tel: +1(212) 584-4662.
License terms

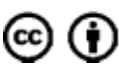




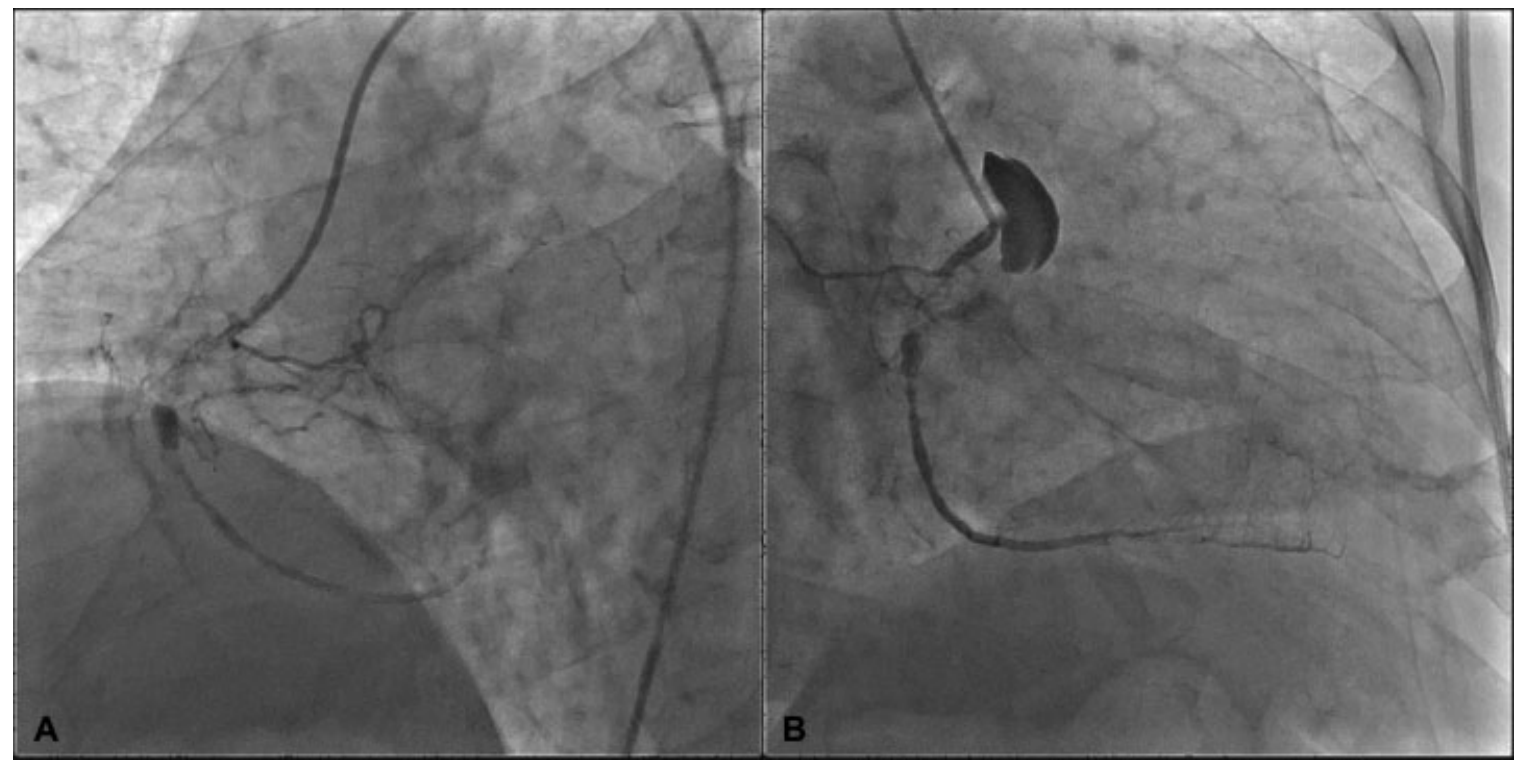

Fig. 1 (A) Origin of the dissection at the proximal right coronary artery. (B) Right anterior oblique (RAO) view showing the extension of the dissection to ascending aorta.

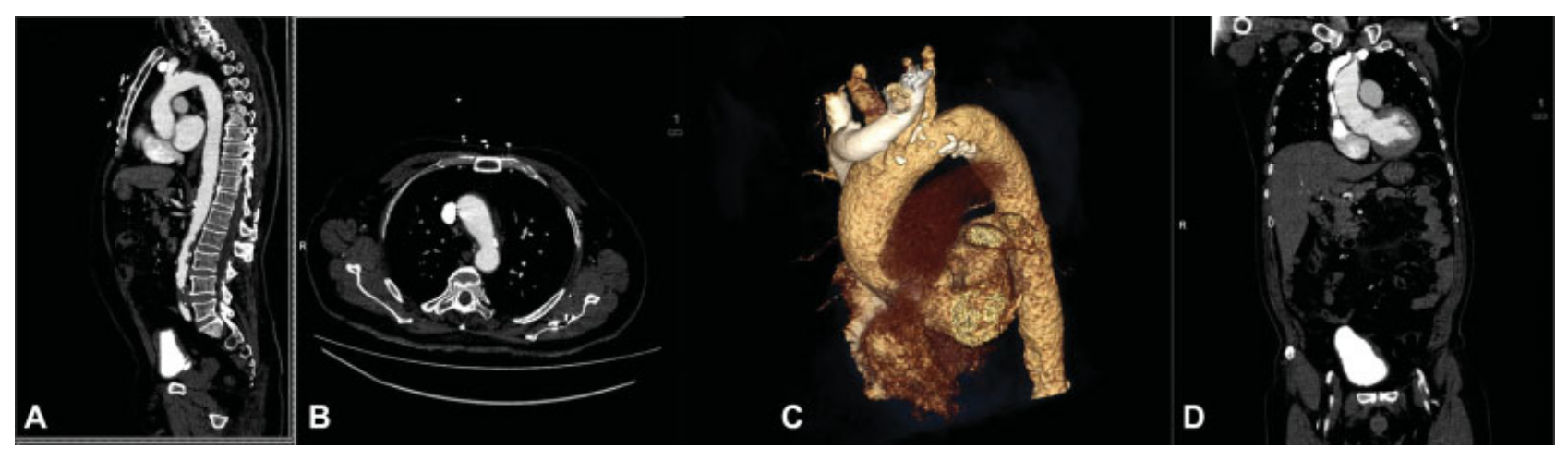

Fig. 2 Transverse (A), axial (B), axial volume rendered (C), and sagittal (D) Computed tomographic images immediately after coronary angiography showing no evidence of dissection in the ascending aorta.

manipulations or deep engagement of catheters and maintaining a steady tension on the guiding catheter while the angioplasty balloon is withdrawn. ${ }^{4}$ During coronary angiography, the pressure waveform should be monitored to prevent contrast injection in the presence of dampening. If coronary dissection occurs during a diagnostic angiography, exchanging to a guiding catheter with good coaxial alignment should be considered. More importantly, it is essential to stop subsequent contrast injections that could lead to extension and enlargement of the dissection.

In this case, an initial limited iatrogenic dissection of the proximal RCA and subsequent forceful contrast medium injection were the most likely causes of this dissection.

Iatrogenic coronary artery dissections are classified into three forms by Dunning et al. ${ }^{5}$ Coronary stenting is the recommended management strategy for classes I (cusp only) and II (up the aortic wall $<4 \mathrm{~cm}$ ) dissections. Class III (up the aortic wall $>4 \mathrm{~cm}$ ) dissections should be preferably treated surgically, because they involve aortic valve cusps and extend up the aorta. ${ }^{5}$
The appropriate therapeutic strategy for iatrogenic dissections remains controversial being generally based on the type of dissection and the hemodynamic stability of the patient. Some authors have proposed that in all the cases in which there is dissection into the coronary sinus, the ostium should be sealed immediately by ostial stenting. ${ }^{6}$ Others have proposed that surgical intervention should be considered if the dissection extends to $4 \mathrm{~cm}$ or beyond into the aorta. ${ }^{4}$ Spontaneous regression of IADs has also been reported in case of limited IAD, probably due to spontaneous sealing and stagnation of blood flow in the false lumen. ${ }^{7}$ Park et $\mathrm{al}^{8}$ reported a good outcome of a CTO patient who suffered AD involving the entire ascending aorta, successfully managed using a conservative strategy. Indeed, a more recent case was reported by Wykrzykowska et al, ${ }^{9}$ underscoring the strategy consisting of patching up the coronary problem, and "wait and see" in close intervals using the computed tomographic scan or transesophageal echocardiography, if the dissected aortic wall segment will heal. However, it is not possible to know which patient might be conservatively managed with "wait and see" in such a 


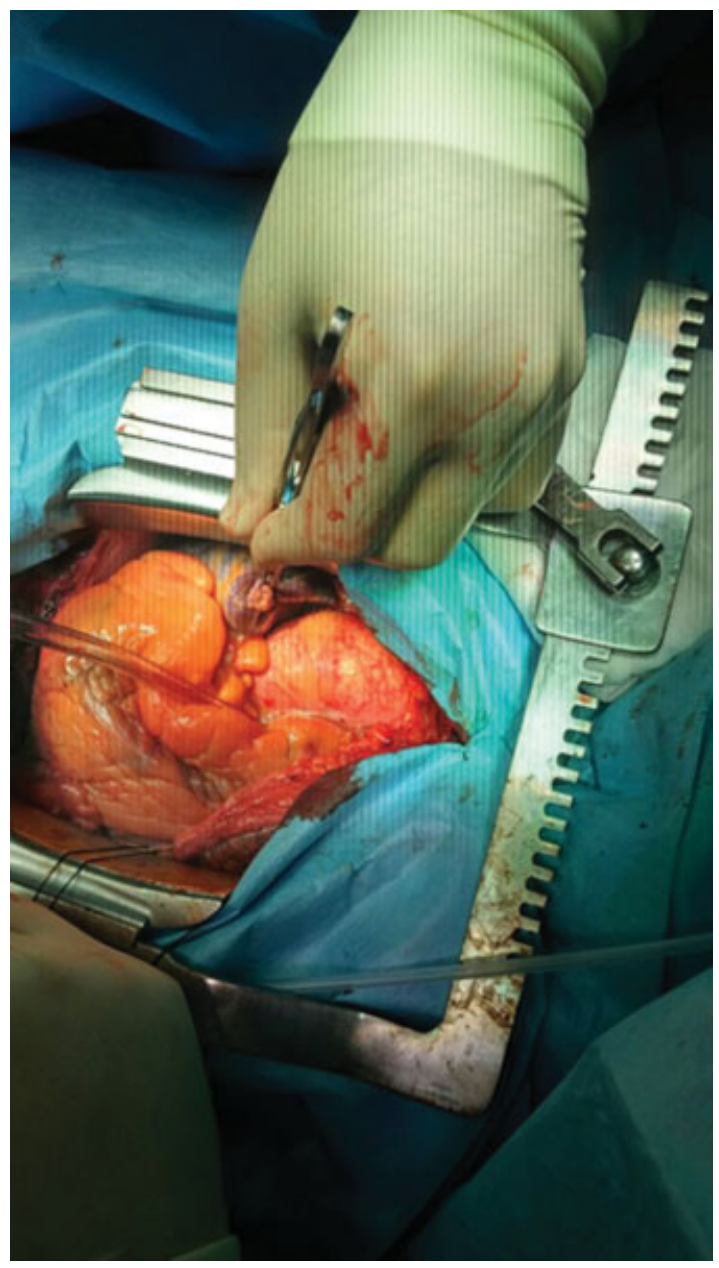

Fig. 3 Intraoperative image of the ascending aorta.

dangerous complication. We think that the extent of dissection is a significant prognostic factor, and in cases such as ours, a relative intact aorta without heavy calcification is the most important factor in spontaneous healing. This case may be useful for cardiologist to avoid RCA stenting or at least to think about the best approach in the case without ischemic and hemodynamic signs.
This case suggests that the selected patients with uncomplicated ascending IADs can be successfully managed by medical therapy alone.

\section{Funding \\ None.}

\section{Conflict of Interest}

The authors declare no conflict of interest related to this article.

\section{Acknowledgements \\ None.}

\section{References}

1 Boukhris M, Tomasello SD, Marzà F, Azzarelli S, Galassi AR. Iatrogenic aortic dissection complicating percutaneous coronary intervention for chronic total occlusion. Can J Cardiol 2015;31(03):320-327

2 Carter AJ, Brinker JA. Dissection of the ascending aorta associated with coronary angiography. Am J Cardiol 1994;73(12):922-923

3 Santos M, Luz A, Silveira J, et al. Aortocoronary dissection complicating percutaneous angioplasty. Rev Port Cardiol 2011;30 (09):745-747

4 Sohrabi B, Kazemi B, Aslanabadi N. Percutaneous treatment of catheter-induced dissection of the right coronary artery and adjacent aortic wall. J Invasive Cardiol 2007;19(07):E199-E202

5 Dunning DW, Kahn JK, Hawkins ET, O'Neill WW. Iatrogenic coronary artery dissections extending into and involving the aortic root. Catheter Cardiovasc Interv 2000;51(04):387-393

6 Carstensen S, Ward MR. Iatrogenic aortocoronary dissection: the case for immediate aortoostial stenting. Heart Lung Circ 2008;17 (04):325-329

7 Roumy A, Kirsch M, Prêtre R, Niclauss L. Spontaneous regression of a large iatrogenic dissection of the ascending aorta. Aorta (Stamford) 2016;4(06):226-228

8 Park IW, Min PK, Cho DK, Byun KH. Successful endovascular treatment of iatrogenic coronary artery dissection extending into the entire ascending aorta. Can J Cardiol 2008;24(11):857-859

9 Wykrzykowska JJ, Ligthart J, Lopez NG, Schultz C, Garcia-Garcia H, Serruys PW. How should I treat an iatrogenic aortic dissection as a complication of complex PCI? EuroIntervention 2012;7(09): 1111-1117 